American J. of Engineering and Applied Sciences 4 (2): 235-243, 2011

ISSN 1941-7020

(C) 2011 Science Publications

\title{
Application of Adaptive Predictive Control to a Newborn Incubator
}

\author{
Med Aymen Zermani, Elyes Feki and Abdelkader Mami \\ Department of Electric Engineering, \\ Laboratory of Analysis and Control of Systems, \\ National School of Engineering of Tunis, Tunis, Tunisie
}

\begin{abstract}
Problem statement: This study presents an application of Indirect Adaptive Generalized Predictive Control (IAGPC) of an incubator for newborn, in order to improve the performance of temperature control. Approach: Analysis of physical phenomena of incubator was involved together knowledge of the dynamic behavior. Incubator was identified by means of Recursive Least Square (RLS) technique associated with a projection of the model parameters for robust system identification. Results: Results showed that mathematical model of neonatal incubator predicted coincide with the measured data. A comparative study was made between ON-OFF, PID and IAGPC control in order to provide the performance of each strategy. Conclusion: Results had proved effectiveness of the IAGPC as a control of incubator system.
\end{abstract}

Key words: Neonatal incubator, temperature, identification, control, Recursive Least Square (RLS), Generalized Predictive Control (IAGPC), transpidermal respiratory, physical phenomena, heating resistance, Generalized Predictive Controller (GPC)

\section{INTRODUCTION}

The First Published Report of an Incubator for use in the care of the premature infant by Thomas et al. (1857) At this time, he had the idea to run a cradle zinc called incubator, in which it was possible to maintain a constant heat and to keep the baby warm. Therefore temperature is one of the most important factors that need to be maintained with minimum variation to keep the transpidermal respiratory and water loss to a minimum level and to increase the heat storage body (Bach et al., 1999). At this time, the neonatal incubator keeps the newborn or premature infants in a suitable atmosphere in terms of temperature, humidity and oxygenation and thus protect, as much as possible from external aggression as germs and noise. This development is due to technological progress, seen in these last years. Furthermore, the current commercial devices use a classical control as the on-off or PID control (Thomas, 1999). But this type of control does not always achieve the required performance: overshoot and undershoot in the air temperature (Silva et al., 2006; Rddy et al., 2009). The question remains if we use an advanced control strategy, we can be provide suitable environment for premature born infants and maintained the temperature that is set by the doctor without significant variation over time whatever disturbance.

The purpose of the present study was to address this question by generalized predictive control. In this case, a development of an accurate model is essential.
The modeling is to gather knowledge that has the dynamic behavior of process, by analysis of physical phenomena involved. The study of system nonlinearities is considered as parametric uncertainty where the need for adaptive control. To do this we have achieved and implemented a control system based on a microcontroller. In this study, an overview of the product was presented. After that, an incomplete physical model of the incubator shows the complexity of the process and the parametric model has been developed. As a control, we opted for the Indirect Adaptive Generalized Predictive Control IAGPC, the control law for the incubator is described and simulations examples are illustrated. Finally, a comparative study was made between PID and ONOFF and IAGPC control in order to show the performance of each strategy.

\section{MATERIALS AND METHODS}

This application concerns an AIR-SHIELDS C100 INCUBATOR located in Higher Institute of Medical Technologies of Tunis.

In order to collect relevant data then to estimate the parameters of mathematical model and to test the control law, a system of identification and control was constructed. The system mainly consists of four units: the incubator AIR-SHIELD chamber, the acquisition board, the controller board and the computer.

Corresponding Author: Med Aymen Zermani, Department of Electric Engineering, Laboratory of Analysis and Control of Systems, National School of Engineering of Tunis, Tunis, Tunisie 




Fig. 1: The process of identification and control of heating in a premature infant incubator

In Fig. 1 we based our design on a system able to put our process in open-loop (modeling) or closed loop (control) (Zermani et al., 2011). The experimental device consists of putting the incubator in open loop which allows having a flow of air with space heater characteristics. The air is warmed in the contact with a heating resistance. The fan is turned on and allows air circulation inside the incubator. The internal temperature measurement is based on T-type LM35. The sensor resistance value is converted to a voltage signal and amplified to suit the acquisition board that communicate with the computer through parallel port DB25. The heater output needs to be controlled in order to control the temperature of the system. This is done with the phase angle control provided by a microcontroller PIC 16F77. A RS232 link is used to communicate between the controller board and the computer.

Physical model for incubator: In the literature, several physical models of the incubator have been made (Taweel and Amer, 2006) but which of them is suitable for control synthesis? To answer this question, we began by gathering and analyzing knowledge of the dynamic behavior of process. This analysis leads to the definition of the model structure Fig. 2.

The phenomena occurring in the heat of the incubator are as follow:

- The convective exchange with the outside air

- The radiative exchange with the outside air

- The convective exchange with the inside air

- The radiative exchange between the walls

- Transfer by conduction through completely opaque walls

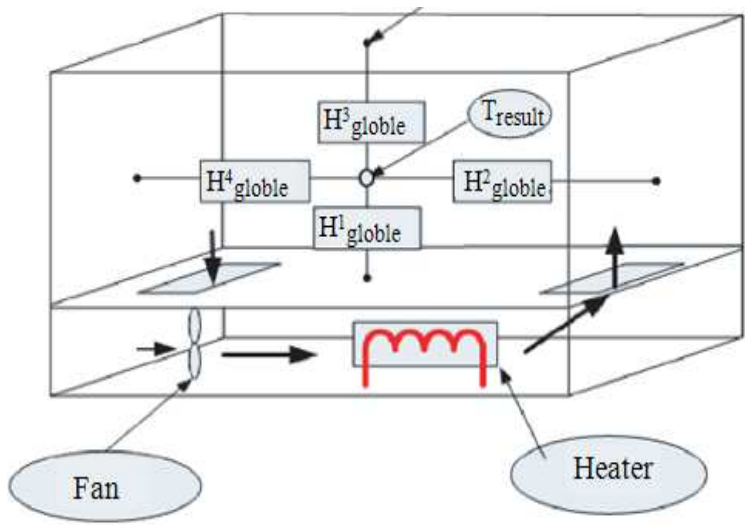

Fig. 2: Physical model incubator representing all heat transfers

Assumption for the model are:

- A Compartment is assumed to be homogenous throughout its material

- The air flow in the incubator air space is considered to be uniform

- All heat transfers are one-way

- Convective and radiative exchanges are expressed by a factor of global exchange

- The walls of the incubator are modeled by a resistor with conduction coefficient Balance of trade with the air resulting node

$(\rho c)_{\text {air }} \mathrm{v}_{\text {air }} \frac{\mathrm{dT}_{\text {result }}}{\mathrm{dt}} \sum_{\mathrm{r}} \mathrm{H}_{\text {globle }} \mathrm{S}_{\mathrm{i}}\left(\mathrm{T}_{\text {p.interne }}-\mathrm{T}_{\text {reult }}\right)$

$+\mathrm{n}(\rho \mathrm{c})_{\text {air }} \mathrm{v}_{\text {air }}\left(\mathrm{T}_{0}-\mathrm{T}_{\text {reult }}\right)+\mathrm{Q}_{\text {vent }}+\mathrm{P}(\mathrm{t})$

The complexities of the physical model, especially those regarding the transfer by conduction through walls and different materials inside and outside the incubator, makes difficult their holdings for the identification and control. To take into account these complexities and uncertainties, the system is seen as a mathematical model and the recursive estimation approach is adopted to estimate parameters in real time.

\section{Nomenclature:}

$\mathrm{p} \quad$ Density of air, $\mathrm{kg} \cdot \mathrm{m}^{-3}$

c Specific mass capacity, $\mathrm{m}^{3} \cdot \mathrm{kg}^{-1}$

$\mathrm{v} \quad$ Volume, $\mathrm{m}^{3}$

$\mathrm{H}_{\mathrm{GLOBAL}}$ Convective and radiative exchanges, $\mathrm{W} . \mathrm{m}^{-2} \cdot \mathrm{K}^{-1}$

$\mathrm{Si} \quad$ Exchange surface, $\mathrm{m}^{2}$

$\mathrm{T}_{\text {p.interne }} \quad$ Air temperature near the walls, $\mathrm{K}$

$\mathrm{T}$ result Temperature resulting node, $\mathrm{K}$

$\mathrm{n} \quad$ Air change rate, $\mathrm{m}^{3} \cdot \mathrm{sec}^{-1}$ 
Am. J. Engg. \& Applied Sci., 4 (2): 235-243, 2011

$\begin{array}{ll}\mathrm{T}_{0} & \text { Outside air temperature, } \mathrm{k} \\ \mathrm{Q}_{\text {vent }} & \text { Flow ventilation heat, } \mathrm{m}^{3} \cdot \mathrm{sec}^{-1} \\ \mathrm{P}(\mathrm{t}) & \text { The applied power proportional to the } \\ & \text { resistor heating, Watt }\end{array}$

\section{RESULTS}

Identification: Generally, there are three categories of models that can be used to simulate and predict the incubator environment. The first category is based on the concept of energy and mass balance (Taweel and Amer, 2006; Tourneux et al., 2009). The drawback of this method is that these models are difficult to put in practice. The second category is based on the combination of physical and mathematical models with prior knowledge of the system is necessary. The third category is based on computation intelligence such as fuzzy clustering, artificial neural networks and genetic algorithm. Oliveira et al. (2005) used orthogonal basis functions to model the neonatal incubator prototype and Abbas and Leonhardt (2009) al. used a system identification of neonatal incubator based on adaptive ARMAX Technique. In this section an identification procedure for the newborn incubator is achieved and a linear model is computed. Although temperature characteristic is a continuous variable, it was measured and registered at time steps.

In this discrete domain, the incubator system can be modeled in several ways, such as auto regressive models.

$$
\begin{aligned}
& y(k)=-a_{1} y(k-1) \ldots-a_{n} y(k-n)+ \\
& -b_{1 u} y(k-1-d) \ldots+b_{m u} u(k-m-d)+e(k)
\end{aligned}
$$

With d: delay, u: input system, y: output system and e: white noise. Pseudo-Random Binary Sequence (PRBS) signals were designed as input $\mathrm{u}(\mathrm{k})$ and the temperature was designed as output $\mathrm{y}(\mathrm{k})$. All experimental data were recorded with a sampling period of $10 \mathrm{sec}$. The selection of the appropriate orders of the ARX model is crucial and it has been performed by using Akaike Information Criterion (AIC) in the conventional and standard approach (Fukata et al., 2006). The parameters of the ARX model were updated on line using Recursive Least Square (RLS) method (Landau and Gianluca, 2006).

$$
\begin{aligned}
& \mathrm{P}(\mathrm{k})=\frac{1}{\lambda_{1}(\mathrm{k})}[\mathrm{P}(\mathrm{k}-1)- \\
& \frac{\mathrm{P}(\mathrm{k}-1) \varphi(\mathrm{k}) \varphi^{\mathrm{T}}(\mathrm{k}) \mathrm{P}(\mathrm{k}-1)}{\lambda_{1}(\mathrm{k})}{ }_{\lambda_{2}(\mathrm{k})}+\varphi(\mathrm{k}) \varphi^{\mathrm{T}}(\mathrm{k}) \mathrm{P}(\mathrm{k}-1) \\
& \mathrm{K}(\mathrm{k})=\mathrm{P}(\mathrm{k}) \varphi(\mathrm{k})
\end{aligned}
$$

$$
\theta(\mathrm{k})=\theta(\mathrm{k}-1)+\mathrm{K}(\mathrm{k}) \mathrm{y}(\mathrm{k})-\varphi(\mathrm{k})^{\mathrm{T}} \theta(\mathrm{k}-1)
$$

$\theta$ is a vector of parameters to be identified and '(k) is an observation vector which are given by:

$$
\begin{aligned}
& \theta^{\mathrm{T}}=\left[\mathrm{a}_{1}, \mathrm{a}_{1} \ldots \mathrm{a}_{\mathrm{m}} \mathrm{b}_{1}, \mathrm{~b}_{2}, \ldots \mathrm{b}_{\mathrm{n}}\right] \\
& \varphi^{\mathrm{T}}(\mathrm{k})=[-\mathrm{y}(\mathrm{k}-1),-\mathrm{y}(\mathrm{k}-2) \ldots-\mathrm{y}(\mathrm{k}-\mathrm{n}) \\
& \mathrm{u}(\mathrm{k}-1-\mathrm{d}) \ldots \mathrm{u}(\mathrm{k}-\mathrm{d}-\mathrm{m})
\end{aligned}
$$

The algorithm with constant forgetting factor is to choose $\lambda_{1}(\mathrm{k})=\lambda_{1} 1$ and $\lambda_{2}(\mathrm{k})=1$, typical values for- 1 is selected within an interval $(0.95, \ldots, 0.99)$. The effect of $\lambda_{1}$ is to introduce a decreasing weight on the previous data. This is why-1 is known as the forgetting factor. The maximum weight is given to the most recent error. This type of profile suits the identification of slowly time varying systems (Landau and Gianluca, 2006). To excite the heating resistance of the incubator, we used a pseudo random binary sequence. This sequence is generated programmatically. After several trials, we found that the dynamic of warming is much faster than cooling. Thus, we were forced to extend the sequence a little cooling. Figure 3 shows the evolution of the sequence applied (PRBS). The response from the incubator to the excitation is shown in Fig. 4.

The model developed is written as follows:

$\mathrm{y}(\mathrm{k})=0.9458 \mathrm{y}(\mathrm{k}-1)+0.0308 \mathrm{y}(\mathrm{k}-2)$

$+0.0194 \mathrm{u}(\mathrm{k}-4)+0.0071 \mathrm{u}(\mathrm{k}-5)+\mathrm{e}(\mathrm{k})$

Figure 4 shows that the incubator has two dynamics: a dynamic heating and cooling. Hysteresis effect plays a very important role in this dynamic. Indeed, hysteresis is the difference between the curve of rise and fall. The latter is caused by the thermal inertia of various elements of the incubator which is also responsible for the nonlinearity of $T=f(P) \quad(T$ : Temperature, P: Power) which sometimes makes it very difficult to model this relationship by a mathematical equation. This phenomenon explains the modeling error to be taken into account later as a parametric uncertainty.

Indirect Adaptive Generalized Predictive: Control (IAGPC) design: The synthesis of the Generalized Predictive Controller (GPC) suggested by Clarke et al. (1987). This method was used successfully in industrial applications of various forms (Richalet et al., 1978; Dion et al., 1991; Dumur et al., 1997; Filatov Unbedhauen, 2004). The approach of generalized predictive control is based on a dynamic model of type CARIMA (Controlled Auto-Regressive Integrated Moving Average), given by the following form:

$$
\mathrm{A}\left(\mathrm{q}^{-1}\right) \mathrm{y}(\mathrm{k})=\mathrm{q}^{-\mathrm{d}} \mathrm{B}\left(\mathrm{q}^{-1}\right) \mathrm{u}(\mathrm{k}-1)+\mathrm{C}\left(\mathrm{q}^{-1}\right) \frac{\mathrm{e}(\mathrm{k})}{\Delta\left(\mathrm{q}^{-1}\right)}
$$


Am. J. Engg. \& Applied Sci., 4 (2): 235-243, 2011

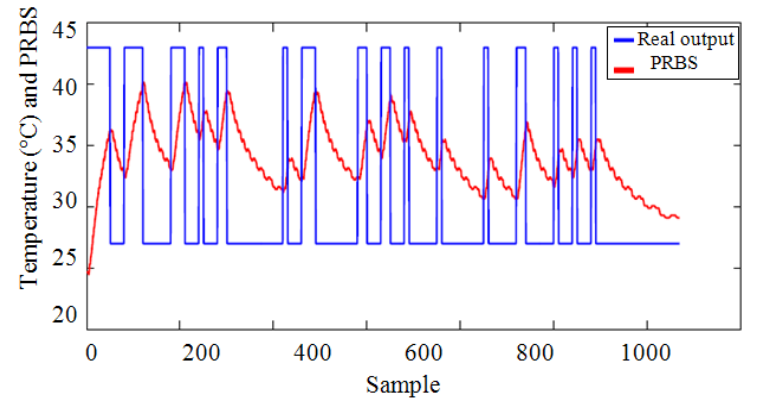

Fig. 3: Data for identification - system input and system output

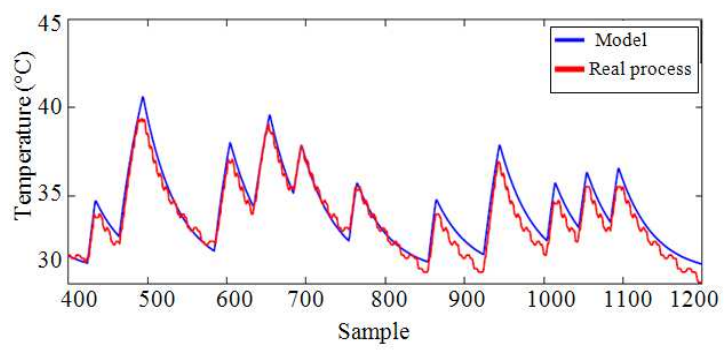

Fig. 4: Real and estimated temperature

$\mathrm{y}(\mathrm{k})$ is the system output, $\mathrm{u}(\mathrm{k})$ the system input, $\mathrm{e}(\mathrm{k})$ the uncorrelated random sequence, $\Delta\left(\mathrm{q}^{-1)}=1-\mathrm{q}^{-1}\right.$ corresponds to an integral action. Its presence in the direct channel allows a zero error in steady state value, $\mathrm{A}\left(\mathrm{q}^{-1}\right), \mathrm{B}\left(\mathrm{q}^{-1}\right)$ and $\mathrm{C}\left(\mathrm{q}^{-1}\right)$ are polynomials. In our case the polynomial $\mathrm{C}$ is equal to 1 .

Cost function: The generalized predictive control based on the minimization of a quadratic criterion on a sliding horizon, which involves a term related to the difference between the predicted output sequence and the sequence of future control (Clarke et al., 1987). The criterion is given by the following relation:

$$
\begin{aligned}
& J=\sum_{j=N 1}^{N_{2}}\left[y_{c}(k+j)-\hat{y}(k+j)\right]^{2} \\
& +\lambda \sum_{j=1}^{N_{C}} \Delta u^{2}(k+j-1)
\end{aligned}
$$

With:

$\hat{\mathrm{y}}(\mathrm{k})=$ The output value predicted at time $\mathrm{k}$

$\mathrm{y}_{\mathrm{c}} \quad=$ The set points values at time $\mathrm{k}$

$\Delta \mathrm{u}(\mathrm{k})=$ The increment of control at time $\mathrm{k}$

$\mathrm{N}_{1}=$ The minimum prediction horizon

$\mathrm{N}_{2}=$ The maximum prediction horizon

$\mathrm{N}_{\mathrm{C}}=$ The control horizon

- $\quad=$ The control-weighting factor
Prediction of the system output: Consider the output expressed by the following equation:

$\mathrm{yF}(\mathrm{k})=\mathrm{F}\left(\mathrm{q}^{-1}\right) \mathrm{y}(\mathrm{k})$

Using both Eq. 9 and 11 the output at time $(k+j)$ will be:

$\mathrm{yF}(\mathrm{k}+\mathrm{j})=\frac{\mathrm{F}\left(\mathrm{q}^{-1}\right) \mathrm{B}\left(\mathrm{q}^{-1}\right)}{\mathrm{A}\left(\mathrm{q}^{-1}\right)} \mathrm{u}(\mathrm{k}+\mathrm{k}-\mathrm{d}-\mathrm{a})$

$+\frac{F\left(q^{-1}\right) C\left(q^{-1}\right)}{A\left(q^{-1}\right) \Delta\left(q^{-1}\right)} e(k+j)$

By applying the Euclidean algorithm on the second term of Eq. 12 we get:

$\frac{F\left(q^{-1}\right) C\left(q^{-1}\right)}{A\left(q^{-1}\right) \Delta\left(q^{-1}\right)}=L_{j}\left(q^{-1}\right)+q^{-j} \frac{G_{j}\left(q^{-1}\right)}{A\left(q^{-1}\right) \Delta\left(q^{-1}\right)}$

Using Eq. 9, 13 and we assuming that the term related to the disturbance is zero, the optimal predictor of the output is written as follows:

$\hat{y} F(k+j)=-\frac{L_{j}\left(q^{-1}\right) B\left(q^{-1}\right) \Delta\left(q^{-1}\right)}{C\left(q^{-1}\right)}$

$\mathrm{u}(\mathrm{k}+\mathrm{j}-1-\mathrm{d})+\frac{\mathrm{G}_{\mathrm{j}}\left(\mathrm{q}^{-1}\right)}{\mathrm{C}\left(\mathrm{q}^{-1}\right)} \mathrm{y}(\mathrm{k})$

A second Diophantine equation decompose the predictor in two terms: a term based on the current output, old orders, the system output and a second term dependent on future orders.

$\frac{\sigma\left(q^{-1}\right)}{C\left(q^{-1}\right)}=H_{J}\left(q^{-1}\right)+q^{-j+d} \frac{R_{j}\left(q^{-1}\right)}{C\left(q^{-1}\right)}$

With:

$\sigma\left(\mathrm{q}^{-1}\right)=\mathrm{L}_{\mathrm{j}}\left(\mathrm{q}^{-1}\right)+\mathrm{B}\left(\mathrm{q}^{-1}\right)$

The optimal predictor of the output is written as follows:

$\hat{y} F(k+j)=H_{j}\left(q^{-1}\right) \Delta\left(q^{-1}\right) u(k+j-d-1)$

$\frac{\mathrm{G}_{\mathrm{j}}\left(\mathrm{q}^{-1}\right)}{\mathrm{C}\left(\mathrm{q}^{-1}\right)} \mathrm{y}(\mathrm{k})+\frac{\mathrm{R}_{\mathrm{j}}\left(\mathrm{q}^{-1}\right)}{\mathrm{C}\left(\mathrm{q}^{-1}\right)} \Delta\left(\mathrm{q}^{-1}\right) \mathrm{u}(\mathrm{k}-1)$

where, $\operatorname{Hj}\left(\mathrm{q}^{-1}\right), \quad \mathrm{Gj}\left(\mathrm{q}^{-1}\right), \quad \operatorname{Rj}\left(\mathrm{q}^{-1}\right)$ et $\operatorname{Lj}\left(\mathrm{q}^{-1}\right)$ are polynomial solutions to the Diophantine equation (Astrom, 1983). 
The matrix formulation is represented in (18):

$$
\hat{\mathrm{y}}(\mathrm{k})=\hat{\mathrm{H}}_{\mathrm{j}} \Delta \mathrm{U}(\mathrm{k}) \frac{\hat{\mathrm{G}}_{\mathrm{y}}(\mathrm{k})+\hat{\mathrm{R}} \Delta \mathrm{u}(\mathrm{k}-1)}{\mathrm{C}\left(\mathrm{q}^{-1}\right)}
$$

With:

$$
\begin{aligned}
& \Delta \mathrm{U}=\left[\Delta \mathrm{u}(\mathrm{k}) \ldots \Delta \mathrm{u}\left(\mathrm{k}+\mathrm{N}_{\mathrm{c}}-1\right)\right]_{\mathrm{T}} \\
& \hat{\mathrm{G}}=\left[\mathrm{G}_{1+\mathrm{d}}\left(\mathrm{q}^{-1}\right) \ldots \mathrm{G}_{\mathrm{N} 2+\mathrm{d}}\left(\mathrm{q}^{-1}\right)\right]^{\mathrm{T}} \\
& \hat{\mathrm{R}}=\left[\mathrm{R}_{1+\mathrm{d}}\left(\mathrm{q}^{-1}\right) \ldots \mathrm{R}_{\mathrm{N} 2+\mathrm{d}}\left(\mathrm{q}^{-1}\right)\right]^{\mathrm{T}} \\
& \hat{\mathrm{H}}=\left(\begin{array}{cccc}
\mathrm{h}_{0} & 0 & \ldots & 0 \\
\mathrm{~h}_{1} & \mathrm{~h}_{0} & \ldots & 0 \\
\ldots & \ldots & \ldots & \ldots \\
\mathrm{h}_{\mathrm{N} 2-1} & \mathrm{~h}_{\mathrm{N} 2-2} & \ldots & \mathrm{h}_{\mathrm{N} 2-\mathrm{NC}}
\end{array}\right)
\end{aligned}
$$

Law order: We can write the criterion $\mathrm{J}$ in matrix form:

$$
\mathrm{J}=\left[\hat{\mathrm{Y}}(\mathrm{k})-\mathrm{y}_{\mathrm{c}}(\mathrm{k})\right]^{\mathrm{T}}\left[\hat{\mathrm{Y}}(\mathrm{k})-\mathrm{y}_{\mathrm{c}}(\mathrm{k})\right]+\lambda \Delta \mathrm{U}(\mathrm{k})^{\mathrm{T}} \Delta \mathrm{U}(\mathrm{k})
$$

With:

$$
Y_{c}=\left[y_{c}\left(k+N_{1}+d\right) \ldots y_{c}\left(k+N_{2}+d\right)\right]
$$

The optimal control law is derived from analytical minimization of the previous cost function. Only the first control value is finally applied to the system.

$\mathrm{u}(\mathrm{k})=\mathrm{u}(\mathrm{k}-1)+\mathrm{m}_{\mathrm{GPC}}^{\mathrm{T}}\left[\mathrm{Y}_{\mathrm{c}}(\mathrm{k})+\frac{-\hat{\mathrm{G}}_{\mathrm{y}}(\mathrm{k})-\hat{\mathrm{R}} \Delta \mathrm{u}(\mathrm{k}-1)}{\mathrm{C}\left(\mathrm{q}^{-1}\right)}\right]$

Which: $\mathrm{m}_{\mathrm{GPC}}^{\mathrm{T}}$ represents the first line of $\left(\hat{\mathrm{H}}^{\mathrm{T}} \hat{\mathrm{H}}+\lambda \mathrm{I}_{\mathrm{Nc}}\right)^{-1} \hat{\mathrm{H}}^{\mathrm{T}}$ and $\mathrm{I}_{\mathrm{Nc}}$ is diagonal matrix of size $\mathrm{Nc} * \mathrm{Nc}$

$$
\mathrm{I}_{\mathrm{Nc}}=\left(\begin{array}{ll}
1 & 0 \\
0 & 1
\end{array}\right)
$$

Adaptive control: The synthesis of the previous predictive control considers that the parameters of the process are fixed, but in reality this is not the case. These parameters vary over time a slow variation affecting the controller performance. The adaptive predictive controller which is proposed by the bloc diagram flow is an indirect controller (Astrom, 1983; De Mathelin and Lozano, 1999). The least-squares (RLS) algorithm is applied to estimate the unknown system parameters $\mathrm{A}^{\wedge}$ and ${ }^{\wedge} \mathrm{B}$, after that the estimated parameters are updated at each sampling period for tuning of the GPC control $\mathrm{H}_{\mathrm{j}}, \mathrm{G}_{\mathrm{j}}, \mathrm{R}_{\mathrm{j}}$ and $\mathrm{L}_{\mathrm{j}}$. The procedure is iterated while the new output is available.

The application of adaptive control is based on a priori knowledge of the process. The start of the command is rather difficult. Both approaches of starting the adaptive predictive control most used in practice are: starting with an estimated independent command or starting with adjusting the sampling period. In our case we use the first approach. This technique recommends the use of an independent monitor of the estimated parameters at the outset. Therefore predictive adaptive control is used only when the estimates converges to the true values. This avoids the oscillation control signal due to rapid variation of parameters estimated.

Control problem statement: When there are no disturbances and noise and when the parameters are constant most adaptive control algorithms have good convergence and stability. In addition, we hope that this performances will be preserved in presence of modeling error and presence of delay. This error can be an hysteresis effect that characterize most of thermal system which cause the change of system dynamics. However, in the presence of bounded disturbances, noise and time-varying parameters not even stability of the recursive estimation algorithm can be guaranteed. So, the use of the RLS estimated without modification can be dangerous especially in the absence of persistent excitation in presence of slow perturbation and small modeling errors. Therefore, it must modify the estimation so that it can not diverge. Given:

$$
\left.\mathrm{y}(\mathrm{k})=\frac{\mathrm{q}^{-\mathrm{d}} \mathrm{B}\left(\mathrm{q}^{-1}\right)}{\mathrm{A}\left(\mathrm{q}^{-1}\right)} 1+\mathrm{H}^{*}\right) \mathrm{u}(\mathrm{k} /-1)+\mathrm{e}(\mathrm{k})
$$

With e representing an external perturbation and the operator $\mathrm{H}$ - which is arbitrary (linear or not, variant or not) (Chaoui and Saad, 2001). We assume that:

- The static gain $\frac{\mathrm{B}(1)}{\mathrm{A}(1)}$

- $\quad \Delta\left(\mathrm{q}^{-1}\right)$ and $\mathrm{B}\left(\mathrm{q}^{-1}\right)$ are coprime

- $\mathrm{A}\left(\mathrm{q}^{-1}\right)$ is a hurwitz operator $\mathrm{A}\left(\mathrm{z}^{-1}\right)=0 \Rightarrow|\mathrm{z}|<$

- A real number $\rho^{*}$ such as $\|\theta\| \leq \rho *$

The regression form of the model is as follow:

$\mathrm{y}(\mathrm{k})=\varphi(\mathrm{k})^{\mathrm{T} \theta}+\mu$

On the other hand:

$C_{1}=\left[\theta_{1} \ldots \theta_{n}\right]^{T} \in R^{2 n-1} / \theta_{1}+\ldots+\theta_{n}>0$ 
Am. J. Engg. \& Applied Sci., 4 (2): 235-243, 2011

$\mathrm{C}_{2}=\left\{\theta_{1} \in \mathrm{R}^{2 \mathrm{n}-1} /\|\theta\| \leq \rho^{*}\right\}$

$\mathrm{C}^{*}=\mathrm{C}_{1} \cap \mathrm{C}_{2}$

$\mathrm{C}^{*}$ is a known convex and compact:

The Least squares algorithm with projection is as follow:

$$
\begin{aligned}
& \mathrm{P}(\mathrm{k})=\frac{1}{\lambda_{1}(\mathrm{k})}[\mathrm{P}(\mathrm{k}-1)- \\
& \frac{\mathrm{P}(\mathrm{k}-1) \varphi(\mathrm{k}) \varphi^{\mathrm{T}}(\mathrm{k}) \mathrm{P}(\mathrm{k}-1)}{\frac{\lambda_{1}(\mathrm{k})}{\lambda_{2}(\mathrm{k})} \varphi(\mathrm{k}) \varphi^{\mathrm{T}}(\mathrm{k}) \mathrm{P}(\mathrm{k}-1)}
\end{aligned}
$$

$\mathrm{K}(\mathrm{k})=\mathrm{P}(\mathrm{k}) \varphi(\mathrm{k})$

$\theta(\mathrm{k})=\theta(\mathrm{k}-1)+\mathrm{K}(\mathrm{k})\left(\mathrm{y}(\mathrm{k})-\varphi(\mathrm{k})^{\mathrm{t}} \theta(\mathrm{k}-1)\right.$

$\theta(\mathrm{k})=\operatorname{projC} *(\theta(\mathrm{k}) \mathrm{P})$

This algorithm is guarded against any divergence estimated by means of a projection within convex set $\mathrm{C} \subset \mathrm{R}^{2 \mathrm{n}}$ to ensure that this projection preserves the qualities of the original estimate, we must ensure the convex contains the true vector's parameter.

We assumed that the lower $\mathrm{Ij}$ and upper $\mathrm{Sj}$ limits of each element $j$ are known so that $I_{j} \leq j \leq S_{j}$ where $S_{j}$ and $I_{j} \in R$ and $j=1, \cdots \cdots, 4$.

$\theta(\mathrm{k})^{\mathrm{T}}=\left[\begin{array}{llll}\theta_{1} & \theta_{2} & \theta_{3} & \theta_{4}\end{array}\right]$

$=\left[\begin{array}{llll}a_{1} & a_{2} & b_{1} & b_{2}\end{array}\right]$

The orthogonal term-by-term projection is then given by:

$\theta(\mathrm{k})=\operatorname{projc} *(\theta(\mathrm{k}) \mathrm{P})=\left\{\begin{array}{c}\theta_{\mathrm{j}}, \mathrm{I}_{\mathrm{j}} \leq \theta_{\mathrm{j}} \leq \mathrm{S}_{\mathrm{j}} \\ \mathrm{I}_{\mathrm{j}}, \theta_{\mathrm{j}} \leq \mathrm{I}_{\mathrm{j}} \\ \mathrm{S}_{\mathrm{j}}, \mathrm{S}_{\mathrm{j}} \leq \theta_{\mathrm{j}}\end{array}\right\}$

Result and discussion of IAGPC, PID and on-of controllers: The IAGPC, PID and ON-OF controllers have been applied to the incubator system in pediatric room. The objective of this study is to find a more appropriate control law to obtain a thermal comfort environment. Real time results will give the limit of each controller. The simplest control algorithm which does not need any tuning effort is the ON-OF control. So the control input is equal to 100 percent of power when the temperature inside the incubator is below the set point furthermore, it is $\mathrm{OFF} \mathrm{u}(\mathrm{k})=0$.

The PID control is given by this expression:

$$
\mathrm{u}(\mathrm{k})=\mathrm{K}_{\mathrm{p}} \mathrm{e}(\mathrm{k})+\mathrm{K}_{\mathrm{i}} \sum_{\mathrm{l}=0}^{\mathrm{k}} \mathrm{e}(\mathrm{l})+\mathrm{K}_{\mathrm{d}}(\mathrm{e}(\mathrm{k})-\mathrm{e}(\mathrm{k}-1))
$$

where, $K_{p}, K_{i}$ and $K_{d}$ represents respectively the proportional gain, the integral gain and the derivative gain. Great effort is necessary to choose the right values of gain. The following PID parameters values were used in this study $\mathrm{K}_{\mathrm{p}}=7.2, \mathrm{~K}_{\mathrm{i}}=0.1$ and $\mathrm{K}_{\mathrm{d}}=2.5$. This choice is based on Ziegler-Nichols tuning rule (Landau and Gianluca, 2006). Concerning the IAGPC algorithm, the model parameters were initialized by zero vectors and the covariance matrix $\mathrm{P}(0)=106$ with fixing the forgetting $-1=0.95$. We fixed the parameters of predictive control synthesis essentially by the simulation: the minimum prediction horizon $\mathrm{N} 1=\mathrm{d}$, the maximum prediction horizon $\mathrm{N} 2=15$, the control horizon $\mathrm{NC}=1$ and the control-weighting factor $-=1$. More detailed information may be found in (Clarke et al., 1987). The robust identification algorithm and the GPC programme have been developed in Matlab 7.4. The estimate of the heating model parameters and the update law parameters are performed with a step sampling of 10s. Responses of the temperature inside the incubator controlled by IAGPC, PID and ON-OFF controller are given in the following figure.

\section{DISCUSSION}

In the present study the ON-OFF control showed higher fluctuations in the air temperature. The offset band between the set point and the inside temperature is 4C. This fluctuations decrease and the ON-OFF cycling is reduced if a hysteresis band was adopted. On the other side the offset band caused by IAGPC and PID is negligible. The rise time with the On-OFF controller was 250s, with the PID was 1500s and with IAGPC was 600.

Figure 5 represented the indirect adaptive generalized predictive control strategy witch the a recursive estimation approach was adopted to estimate in real time the system parameters and to adapt at the same time the GPC controller parameters.

Figure 6 shown a good performance control GPC when there are no disturbances and noise and when the parameters are constant. The temperature is closed to the different set points. For Fig. 6-8, it is clear that the behavior of the IAGPC is greater than others two controllers in many aspect. The IAGPC has a speed response to close to the different set points. The robustness of this strategy can be observed through overshoot and the fluctuation rejection, this is not the case of PID or ON-OFF controllers. This can be 
explained by the predictive effect of the GPC: when the heater is closed, (when the temperature is below the set point), the effect of heater continues to be felt. Since this effect is not predicted in conventional PID or ONOFF control, the calculating of the cooling action is not appropriate, so showed the oscillation. Now let as show in Fig. 8-9 the performance of PID and IAGPC when the incubator clappers open for regular treatment such as providing medicine, nutrition or visual inspection of newborn. From the sample 500, the hand ports was opened. The temperature initially dropped then rised, the optimal value is $10 \mathrm{~min}$ for IAGPC and $13 \mathrm{~min}$ for PID.

So through Fig. 9 we can conclude that the IAGPC is more efficient than PID in disturbance rejection.

Most of the time the controller is designed to meet specifications in steady state. In practice, the operation of an incubator is not maintained at a constant speed, but evolves with the physiological status of the newborn.

Some examples of mathematical models based on simplified configuration of human body are: Gagge's tow mode model (core and shell), Wyndham and yamamoto's tree part model. In this study, an adaptive model was considered so that the thermal dynamic properties of the premature infant were evaluated using adaptive system identification. This technique is very important to update the parameters model that depend on infant related parameters such size maturity level, metabolic factor, maturity of skin body development also for changing incubator characteristics like single wall, double wall. In the figures we show the importance of the adaptive technique when a change is made on the structure of the model. The IAGPC has succeeded to maintain stability and reduce the fluctuation but not in the case of the GPC.

Comparisons among these three controllers applied to the incubator system are summarized. Table 1 demonstrate that the IAGPC is superior and more appropriate than the other controller

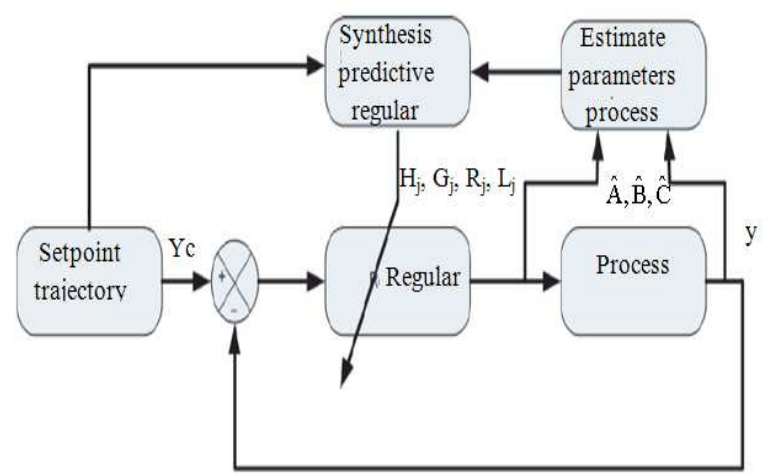

Fig. 5: Structure of the IAGPC

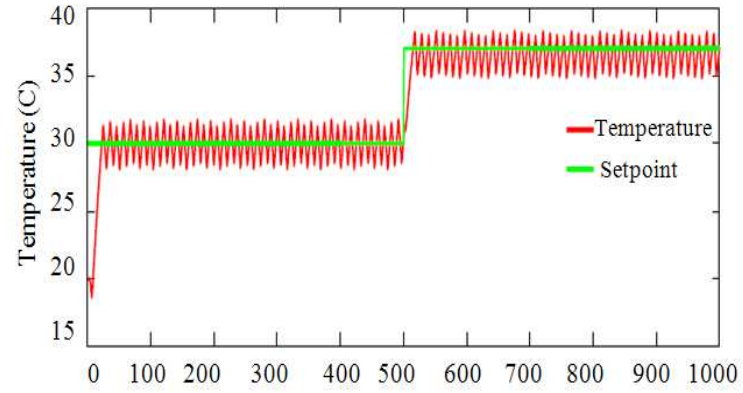

(a)

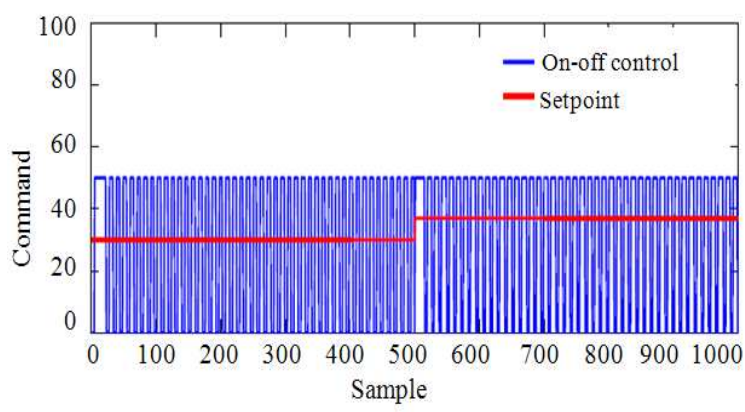

(b)

Fig. 6: Response of the incubator heating system controlled by ON-Off controller

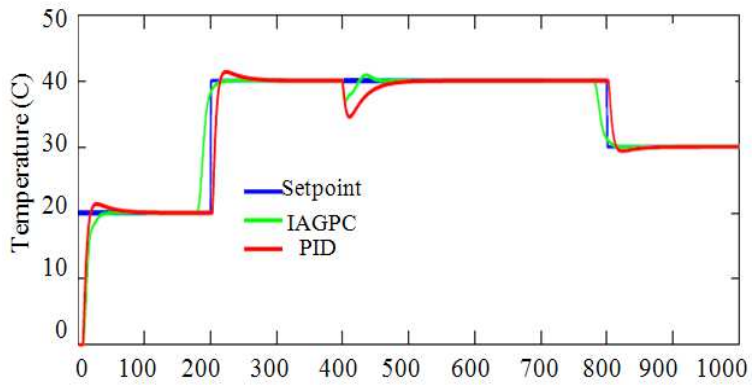

(a)

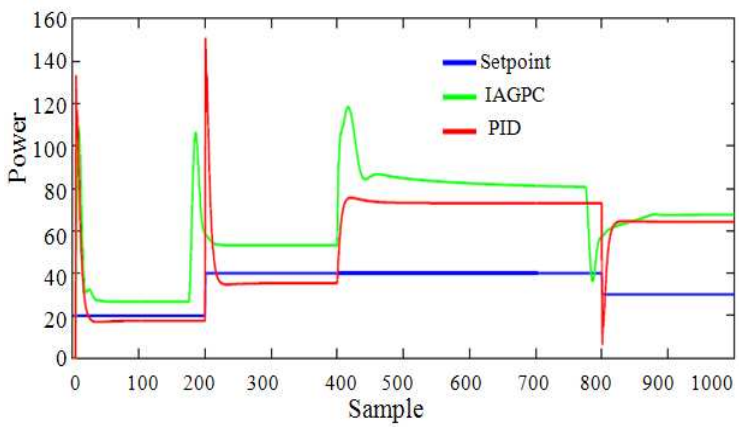

(b)

Fig. 7: Response of the incubator heating system controlled by PID and IAGPC controller 
Am. J. Engg. \& Applied Sci., 4 (2): 235-243, 2011

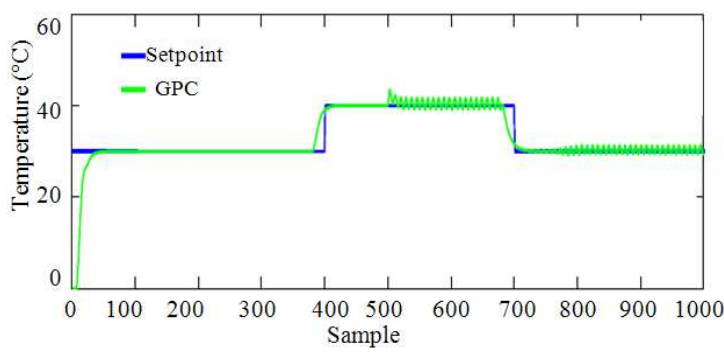

Fig. 8: Response of incubator the heating system controlled by GPC controller with a change made on the structure of the model

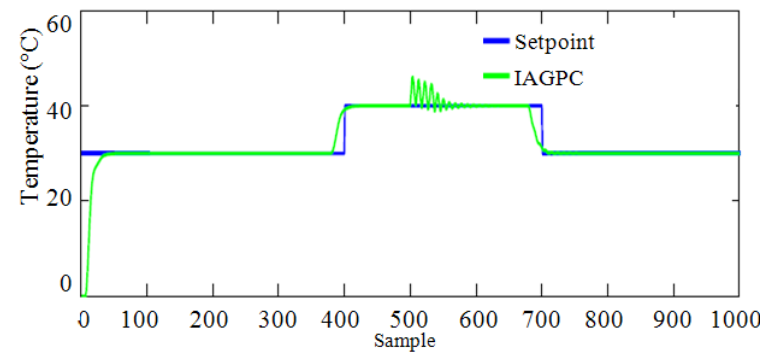

Fig. 9: Response of incubator heating system controlled by IAGPC controller with a change made on the structure of the model

Table 1: Comparison among IAGPC, PID and on-off

\begin{tabular}{llll}
\hline Controller & On-off & PID & IAGPC \\
\hline Tuning effort & None & Considerable & None \\
Response speed & Slow & slow & Fastest \\
$\begin{array}{l}\text { Offset band } \\
\text { On-off cycling }\end{array}$ & very large & large & negligible \\
$\begin{array}{l}\text { Requirement of } \\
\text { adaptive system }\end{array}$ & No & None & None \\
\hline
\end{tabular}

\section{CONCLUSION}

This study focused on the identification and control of an incubator for newborns. In the first part we presented the system identification that achieved to collect relevant data and to implement a different algorithm of control. After that an adaptive system identification was used to determine a model of the incubator. Experimental results show that this model coincide well with the measurement data. At the command, we opted for IAGPC control.

The results of simulation and implementations in real time of the incubator were presented and interpreted. A comparative study was made between IAGPC PID and ON-OFF. Simulation results demonstrate that the IAGPC is superior and more appropriate than the other controllers.

\section{ACKNOWLEDGMENT}

The researchers wish to express their gratitude to Samir Ehmissi from the Maternal and Neonatal Unit of Rabta-Tunis for his contribution and help in the project.

\section{REFERENCES}

Abbas, A.K. and S. Leonhardt, 2009. System Identification of neonatal incubator based on adaptive ARMAX technique. IFMBE Proc., 22: 2515-2519. DOI: 10.1007/978-3-540-89208-3_603

Astrom, K.J., 1983. Theory and applications of adaptive control-A survey. Automatica, 19: 471-486. DOI: 10.1016/0005-1098(83)90002-X

Bach, V., F. Telliez, M. Makk, G. Farges and G. Zoccoli et al., 1999. Contrôle de l'environnement thermique dans les incubateurs pour nouveau-nés prématurés $=$ Temperature control in incubators for preterm neonates. RBM. Revue européenne de biotechnologie médicale. Med., 21: 6-19. http://cat.inist.fr/?aModele $=$ afficheN\&cpsidt $=1773$ 671

Chaoui, F.Z., F. Giri and M.M. Saad, 2001. Adaptive control of input-constrained type-1 plants stabilization and tracking. Automatica, 37: 197203. DOI: 10.1016/S0005-1098(00)00154-0

Clarke, D.W., C. Mohtadi and P.S. Tuffs, 1987. Generalized predictive control-Part I. The basic algorithm. Automatica, 23: 137-148. DOI: 10.1016/0005-1098(87)90087-2

De Mathelin, M. and R. Lozano, 1999. Robust adaptive identification of slowly time-varying parameters with bounded disturbances. Automatica, 35: 12911305. DOI: 10.1016/S0005-1098(99)00026-6

Fukata, K., T. Washio, H. Motoda. and O. Univ., 2006. A method to search arx model orders and its application to sales dynamics analysis. Proceedings of the in 6th IEEE International Conference on Data Mining, Dec. 18-22, IEEE Xplore Press, Hong Kong, pp: 590-595. DOI: 10.1109/ICDMW.2006.10

Landau, Y.D. and G. Zito, 2006. Digital control systems. 1st Edn., Birkhäuser, London, ISBN: 1846280559, pp: 484.

Tourneux, P., J.P. Libert, L. Ghyselen, A. Leke and S. Delanaud et al., 2009. Échanges thermiques et thermorégulation chez le nouveau-né Heat exchanges and thermoregulation in the neonate. Archives Pédiatrie., 16: 1057-1062. DOI: 10.1016/J.ARCPED.2009.03.014, PMID: 19410440 
Oliveira, G.H.C., M.F. Amorim and F.J.. Latawiec, 2005. Multiple model identification and control of neonate incubators using laguerre basis. TUO, Poland.

http://www.nt.ntnu.no/users/skoge/prost/proceedi ngs/ifac2005/Fullpapers/02818.pdf

Rddy, N.P., G. Mathur and S.I. Hariharan, 2009. Toward a fuzzy logic control of the infant incubator. Annals Biomed. Eng., 37: 21462152. DOI:

10.1007/s10439-009-9754-6 PMid:19609677

Silva, A.D., M. Jayathilake, A. Galgomuwa, S. Peiris and L. Udawatta et al., 2006. High performance temperature controller for infant incubators. Proceeding of the in Information and Automation International Conference, Dec. 15-17, IEEE Xplore Press, Shandong, pp: 115-120. DOI: 10.1109/ICINFA.2006.374168
Taweel, A.1. and Y. Amer, 2006. A simulation model of infant-incubator-feedback system with humidification and temperature control. MS Thesis, AUTU University http://aut.researchgateway.ac.nz/handle/10292/975

Thomas, K.A. and R. Burr, 1999. Preterm infant thermal care: differing thermal environments produced by air versus skin servo-control incubators. J. Perinatol., 19: 264-270. DOI: 10.1038/sj.jp.7200183 PMid:10685236

Zermani, M.A., E. Feki and A. Mami, 2011. Application of Genetic Algorithms in identification and control of a new system humidification inside a. newborn incubator. Physice Department, Faculty of

Science. http://www.scribd.com/doc/52440261/Applicationof-Genetic-Algorithms-in-identification-andcontrol-of-a-new-system-humidification-inside-anew-born-incubator 